\title{
Effect of interlayer on silver-induced layer exchange crystalliza- tion of amorphous germanium thin film on insulator
}

\author{
Ryota Yoshimine, Kaoru Toko*, and Takashi Suemasu \\ Institute of Applied Physics, University of Tsukuba, Tsukuba, Ibaraki 305-8573, Japan \\ *E-mail: toko@bk.tsukuba.ac.jp
}

Metal-induced layer exchange (MILE) is an advanced crystallization technique for fabricating high-quality semiconductor thin films on insulating substrates at low temperatures. Here, we focused on $\mathrm{Ag}$ as a catalytic metal for crystallizing amorphous germanium thin films on glass through MILE. The layer exchange between Ag and a-Ge was not simple because Ag diffused into a-Ge so fast that it crystallized the top a-Ge layer before the completion of layer exchange. To suppress Ag diffusion into a-Ge, we explored the kind of interlayer material between them as well as the growth temperature. Preparing $\mathrm{SiO}_{2}$ and $\mathrm{GeO}_{2}$ interlayers allowed for a complete layer exchange, resulting in the formation of polycrystalline Ge thin films on glass at temperatures as low as $250{ }^{\circ} \mathrm{C}$. These findings are essential for further understanding and controlling the layer exchange phenomenon. 


\section{Introduction}

Polycrystalline germanium (poly-Ge) thin films on insulators have attracted the attention of many researchers to realize next-generation electronic devices, such as system-in-displays, three-dimensional integrated circuits, and multijunction thin-film solar cells. ${ }^{1-4)}$ Researchers have developed the following growth techniques for poly-Ge thin films on insulators: magnetron sputtering, ${ }^{4)}$ chemical vapor deposition, ${ }^{5)}$ laser annealing, ${ }^{6,7)}$ and solid-phase crystallization (SPC). ${ }^{8,9)}$ Those poly-Ge thin films, however, consist of small grains $(<1 \mu \mathrm{m})$ and their carrier mobilities are limited to $\left.140 \mathrm{~cm}^{2} \mathrm{~V}^{-1} \mathrm{~s}^{-1} .4,8,9\right)$ In addition, because vacancies in Ge act as acceptors, the poly-Ge thin films are highly p-doped $\left(>5 \times 10^{17} \mathrm{~cm}^{-3}\right){ }^{8,9)}$ The high carrier concentration makes it difficult to control the conduction type.

Metal-induced layer exchange (MILE) has been widely investigated to form largegrained $\mathrm{Si},{ }^{10-15)} \mathrm{SiGe},{ }^{16-18)}$ and $\mathrm{Ge}^{19-30)}$ thin films on insulators. In MILE, $\mathrm{Al}{ }^{19-24)}$ and $\mathrm{Au}{ }^{25-}$ ${ }^{27)}$ have been used as catalytic metals for crystallizing amorphous Ge (a-Ge). The MILE with these catalysts has allowed for the formation of large-grained (>100 $\mu \mathrm{m}),(111)$-oriented $\mathrm{Ge}$ thin films. ${ }^{20,26)}$ In addition, these catalysts have significantly lowered the growth temperature of a-Ge, leading to the formation of poly-Ge on plastic substrates. ${ }^{22,25,26)}$ The use of poly-Ge as a seed layer has enabled us to directly synthesize vertically aligned Ge nanowires on glass ${ }^{28)}$ and plastic substrates. ${ }^{29)}$ However, in an Al-Ge system, the resulting Ge layer shows a high hole concentration of $p=2 \times 10^{20} \mathrm{~cm}^{-3}$ owing to the residual $\mathrm{Al}$ atoms in Ge activated as acceptors. ${ }^{25)}$ Although poly-Ge is useful for a p-type layer in solar cells, ${ }^{12)}$ it cannot be used as an active layer for transistors. On the other hand, in a Au-Ge system, the resulting Ge layer shows relatively good electrical properties $\left(p=2 \times 10^{17} \mathrm{~cm}^{-3}\right.$ and hole mobility: $\left.160 \mathrm{~cm}^{2} \mathrm{~V}^{-1} \mathrm{~s}^{-1}\right){ }^{25)}$ This has allowed for the formation of a thin-film transistor by an all-lowtemperature process. ${ }^{30)}$ However, Au has difficulty in being used for large-area devices because it is expensive and unstable.

We have focused on Ag as a catalytic metal for the MILE growth of a-Ge on insulators. In a Ag-Si system, MILE has been demonstrated. ${ }^{31)}$ Since the solubility of Ag in Ge is low $\left(\sim 10^{5} \mathrm{~cm}^{-3}\right.$ at $\left.250{ }^{\circ} \mathrm{C}\right),{ }^{32)}$ the amount of residual $\mathrm{Ag}$ in Ge should be small. Moreover, the phase diagram of the Ag-Ge system suggests that the layer exchange occurs at low temperatures because $\mathrm{Ge}$ is soluble in $\mathrm{Ag}$ at temperatures lower than those in the case of $\mathrm{Al}$ and $\mathrm{Au}$. In fact, catalytic $\mathrm{Ag}$ has formed crystalline Ge below $400{ }^{\circ} \mathrm{C} .{ }^{33,34)}$ Here, we investigate the 
effect of an interlayer, a diffusion barrier layer between $\mathrm{Ag}$ and $\mathrm{Ge}$, to achieve the layer exchange crystallization of a-Ge on an insulating substrate.

\section{Experimental methods}

Ag films were first prepared on alkaline free glass substrates. Subsequently, an interlayer $\left(\mathrm{Al}_{2} \mathrm{O}_{3}, \mathrm{SiO}_{2}, \mathrm{TiO}_{2}, \mathrm{SiN}\right.$, or $\left.\mathrm{GeO}_{2}\right)$ was prepared as a diffusion control layer. ${ }^{20,25)}$ After that, amorphous $\mathrm{Ge}(\mathrm{a}-\mathrm{Ge})$ films were prepared. The thickness of each Ag or Ge layer was $50 \mathrm{~nm}$ and that of each interlayer was $2 \mathrm{~nm}$. The $\mathrm{Al}_{2} \mathrm{O}_{3}, \mathrm{TiO}_{2}$, and $\mathrm{GeO}_{2}$ interlayers were formed by preparing $\mathrm{Al}, \mathrm{Ti}$, and $\mathrm{Ge}$ followed by air exposure for $1 \mathrm{~d}$, respectively. All depositions were carried out at room temperature by radio-frequency (RF) magnetron sputtering (base pressure: $3.0 \times 10^{-4} \mathrm{~Pa}$ ) using Ar plasma (flow rate: $10 \mathrm{sccm}$, pressure: $0.25 \mathrm{~Pa}$ ). The RF power was set to $30 \mathrm{~W}$ for $\mathrm{Ag}, 100 \mathrm{~W}$ for $\mathrm{SiO}_{2}$, and $50 \mathrm{~W}$ for other materials. The deposition rates were $32 \mathrm{~nm} / \mathrm{min}$ for Ge, $35 \mathrm{~nm} / \mathrm{min}$ for $\mathrm{Ag}, 12.5 \mathrm{~nm} / \mathrm{min}$ for $\mathrm{Al}, 8.7 \mathrm{~nm} / \mathrm{min}$ for $\mathrm{SiO}_{2}, 5$ $\mathrm{nm} / \mathrm{min}$ for $\mathrm{Ti}$, and $6.7 \mathrm{~nm} / \mathrm{min}$ for $\mathrm{SiN}$. In the sputtering system, the error of the deposition thickness is within $10 \%$. Finally, the samples were annealed at 300 or $250{ }^{\circ} \mathrm{C}$ in $\mathrm{N}_{2}$ ambient to induce layer exchange (Fig. 1). The resulting samples were evaluated by Nomarski optical microscopy and Raman spectroscopy (spot size: $1 \mu \mathrm{m}$, wavelength: $532 \mathrm{~nm}$, detection depth: approximately $10 \mathrm{~nm}$ in crystalline Ge). After layer exchange, Ag and interlayers on polyGe were etched away using an acidic solution $\left(\mathrm{H}_{3} \mathrm{PO}_{4}: \mathrm{HNO}_{3}: \mathrm{CH}_{3} \mathrm{COOH}: \mathrm{H}_{2} \mathrm{O}=16: 1\right.$ : 1 : 2) and a HF solution (HF: $1.5 \%$ ) for 1 min each. The resulting Ge layers were evaluated by scanning electron microscopy (SEM), energy-dispersive X-ray (EDX), and electron backscatter diffraction (EBSD).

\section{Results and discussion}

An interlayer between metal and amorphous semiconductor layers is essential for inducing layer exchange and fabricating a high-quality crystalline semiconductor layer on insulators. First, we employ $\mathrm{Al}_{2} \mathrm{O}_{3}$ as an interlayer because it is used in the conventional layer exchange including $\mathrm{Al}-\mathrm{Si},{ }^{11)} \mathrm{Al}-\mathrm{Ge},{ }^{20)}$ and $\mathrm{Au}-\mathrm{Ge} .{ }^{25)}$

Figures 2(a)-2(c) show the Nomarski optical micrographs showing the back surface in 
the samples, observed through transparent substrates. Figure 2(a) shows the bottom Ag layer before annealing. Figure 2(b) shows that dendrite structures appear after $10 \mathrm{~h}$ annealing, which is a representative image of the process of layer exchange. ${ }^{20)}$ However, as shown in Fig. 2(c), those dendrite structures do not grow after annealing for longer than $10 \mathrm{~h}$. The 10h-annealed sample was evaluated by Raman spectroscopy. The representative results are shown in Fig. 2(d). The dendrite structures, observed from the back surface of the sample, had a peak at around $300 \mathrm{~cm}^{-1}$, corresponding to the vibration mode of Ge-Ge bonds. ${ }^{26)}$ This result proves that the dendrite structures are crystalline Ge. On the other hand, Ge-Ge peaks were also observed on the front surface of the sample. This result indicates that the top a-Ge layer crystallized during annealing without layer exchange. From these results, the sample structure is illustrated in Fig. 2(d). Since the crystallization temperature of a-Ge is generally above $400{ }^{\circ} \mathrm{C},{ }^{8,9)}$ this case, the crystallization of the top a-Ge layer at $300{ }^{\circ} \mathrm{C}$, is likely due to the catalytic effect of $\mathrm{Ag}$ atoms. ${ }^{33,34)}$ Therefore, $\mathrm{Ag}$ diffusion into the top a-Ge layer is a possible reason why the dendrite growth, i.e., layer exchange, stopped.

This behavior is explained from the perspective of the diffusion coefficient. The diffusion coefficient is defined as

$$
D=D_{0} \exp \left(-\frac{E}{R T}\right)
$$

where $D$ is the diffusion coefficient $\left(\mathrm{m}^{2} \mathrm{~s}^{-1}\right), D_{0}$ is the diffusion constant $\left(\mathrm{m}^{2} \mathrm{~s}^{-1}\right), E$ is the activation energy of diffusion $\left(\mathrm{kJ} \mathrm{mol}^{-1}\right), R$ is the gas constant $\left(\mathrm{kJ} \mathrm{mol}^{-1} \mathrm{~K}^{-1}\right)$, and $T$ is the absolute temperature $(\mathrm{K})$. Here, $D_{0}$ and $E$ vary between materials where the atoms diffuse. Therefore, $D$ is determined by the material used and the growth temperature. In conventional layer exchange systems (Al-Ge and Au-Ge), the $D$ of metal atoms in $\mathrm{Ge}\left(D_{\text {metal }}\right)$ is smaller than that of $\mathrm{Ge}$ atoms in metals $\left(D_{\mathrm{Ge}}\right) .{ }^{32,35,36)}$ The Ag-Ge system has an opposite property: $D_{\text {metal }}$ is larger than $D_{\mathrm{Ge}}{ }^{32,36)}$ These findings suggest that layer exchange occurs in the system where $D_{\text {metal }}<D_{\mathrm{Ge}}$. We note that $D$ is determined in crystalline Ge or metals. In MILE, metals diffuse into a-Ge and Ge into the grain boundaries of metals. ${ }^{13)}$ There is an assumption that the magnitude relation of $D$ remains unchanged against the crystal state. According to the discussion, if an interlayer material blocks Ag but allows Ge to pass, the layer exchange between $\mathrm{Ag}$ and Ge layers is likely to occur despite $D_{\text {metal }}>D_{\mathrm{Ge}}$. We therefore explored the interlayer material between $\mathrm{Ag}$ and Ge layers for completing layer exchange. 
We employed $\mathrm{SiO}_{2}, \mathrm{TiO}_{2}, \mathrm{SiN}$, or $\mathrm{GeO}_{2}$ as an interlayer material. As shown in Figs. 3(a) and 3(b), when the interlayer was $\mathrm{SiO}_{2}$ or $\mathrm{TiO}_{2}$, dendrite growth stopped. This results in the insufficient coverage of $\mathrm{Ge}$ on the substrate as is the case of the $\mathrm{Al}_{2} \mathrm{O}_{3}$ interlayer. As shown in Fig. 3(c), when the interlayer was SiN, the sample remained unchanged after annealing. This result suggests that the 2-nm-thick SiN layer suppressed the diffusion of both Ge and $\mathrm{Ag}$ atoms. Figure 3(d) shows that, when the interlayer was $\mathrm{GeO}_{2}$, Ge and $\mathrm{Ag}$ were mixed without layer exchange. The mixed structure was determined by the naked eye and Nomarski optical microscopy: both sides of the sample showed the same color and morphology. This result is the same as that observed in the sample without an interlayer. Thus, $\mathrm{Ag}$ and $\mathrm{Ge}$ atoms rapidly passed through the 2-nm-thick $\mathrm{GeO}_{2}$ layer. We varied the thickness of the interlayer from 1 to $5 \mathrm{~nm}$; however, the layer exchange was not achieved. From these results, we conclude that it is difficult to selectively suppress Ag diffusion into Ge only by changing the interlayer material.

As we mentioned above, the diffusion coefficient $D$ also depends on the growth temperature $T$. In addition, its dependence is related to the activation energy $E$, which depends on the kind of material. To suppress Ag diffusion into Ge, we therefore lowered the growth temperature from 300 to $250{ }^{\circ} \mathrm{C}$ for samples with different interlayers. The results are shown in Fig. 4. As shown in Figs. 4(a), 4(c), and 4(d), when the interlayer was $\mathrm{Al}_{2} \mathrm{O}_{3}, \mathrm{TiO}_{2}$, or $\mathrm{SiN}$, growth morphologies were almost the same as those obtained at $300{ }^{\circ} \mathrm{C}$. On the other hand, when the interlayer was $\mathrm{SiO}_{2}$ or $\mathrm{GeO}_{2}$, dendrite growth was completed and covered the entire substrate as shown in Figs. 4(b) and 4(e). These results suggest that the layer exchange was completed because the $\mathrm{SiO}_{2}$ and $\mathrm{GeO}_{2}$ interlayers well suppressed $\mathrm{Ag}$ diffusion into $\mathrm{Ge}$ at $250{ }^{\circ} \mathrm{C}$. Thus, the Ag-induced layer exchange growth of a-Ge was achieved by modulating both the interlayer material and the growth temperature.

After removing the top-Ag layers in the layer-exchanged samples, the crystal quality of the resulting Ge layers was evaluated. As shown in Fig. 5(a), the Ge layers have Ge-Ge peaks whose positions were the same as that of the bulk-Ge substrate. This result suggests that the Ge layers had no stress. The full widths at half maximum (FWHMs) of the Ge layers were relatively small $\left(4.6 \mathrm{~cm}^{-1}\right),{ }^{8,21,26)}$ indicating good crystallinity. Figures $5(\mathrm{~b})$ and $5(\mathrm{c})$ show that the Ge layers cover the glass substrates. The cracks in the Ge layers correspond to the collisions of the grown dendrites, which became obvious during Ag etching. The sample 
prepared with a $\mathrm{GeO}_{2}$ interlayer has small Ge islands on the surface [Fig. 5(b)], which usually appear in layer-exchanged $\mathrm{Si}^{10)}$ and $\mathrm{Ge}^{23)} \mathrm{In}$ contrast, the sample with a $\mathrm{SiO}_{2}$ interlayer has a smooth surface without Ge islands [Fig. 5(a)]. For the latter sample, Ge islands are considered to be removed together with Ag by wet etching likely because of the poor interface adherence between the Ge islands and the $\mathrm{SiO}_{2}$ interlayer. ${ }^{5)}$ As a result of the EDX measurement, the Ag concentration in the Ge layers was lower than the detection limit (1\%), attributed to the low solubility of $\mathrm{Ag}$ in Ge. ${ }^{32)}$ Figures 5(d) and 5(e) show that the grain size of the Ge layers in both samples is approximately a few $\mu \mathrm{m}$. This grain size is two orders larger than that of conventional SPC-Ge ${ }^{8,9)}$ however, it is smaller than that of the Ge layers obtained by Al- and Au-induced layer exchange. ${ }^{20,25)}$ Further optimization of growth conditions is necessary to improve the crystal quality of the Ge layer obtained by Ag-induced layer exchange.

\section{Conclusions}

We focused on Ag as a catalytic metal for the MILE growth of a-Ge. We found that the layer exchange between $\mathrm{Ag}$ and Ge was not simple because Ag diffused into Ge so fast that it crystallized the top a-Ge layer before layer exchange. By selecting appropriate interlayers $\left(\mathrm{SiO}_{2}\right.$ and $\left.\mathrm{GeO}_{2}\right)$ between the $\mathrm{Ge}$ and $\mathrm{Ag}$ layers and by lowering the growth temperature from 300 to $250{ }^{\circ} \mathrm{C}$, we achieved a complete layer exchange growth of a-Ge on a glass substrate. These findings are essential for understanding the layer exchange mechanism and for fabricating high-quality semiconductor thin films on insulating substrates.

\section{Acknowledgments}

This work was financially supported by the JSPS KAKENHI Grant Number 26709019, the Nanotech CUPAL, and the Iketani Science and Technology Foundation. Some experiments were conducted at the International Center for Young Scientists and the Molecule \& Material Synthesis Platform in NIMS. 


\section{References}

1) T. Sadoh, H. Kamizuru, A. Kenjo, and M. Miyao, Appl. Phys. Lett. 89, 192114 (2006).

2) M. Uenuma, B. Zheng, K. Bundo, M. Horita, Y. Ishikawa, H. Watanabe, I. Yamashita, and Y. Uraoka, J. Cryst. Growth 382, 31 (2013).

3) S. Kabuyanagi, T. Nishimura, K. Nagashio, and A. Toriumi, Thin Solid Films 557, 334 (2014).

4) C.-Y. Tsao, J. Huang, X. Hao, P. Campbell, and M. A. Green, Sol. Energy Mater. Sol. Cells 95, 981 (2011).

5) M. Tada, J. H. Park, J. R. Jain, and K. C. Saraswat, J. Electrochem. Soc. 156, D23 (2009).

6) W. Yeh, H. Chen, H. Huang, C. Hsiao, and J. Jeng, Appl. Phys. Lett. 93, 094103 (2008).

7) K. Sakaike, S. Higashi, H. Murakami, and S. Miyazaki, Thin Solid Films 516, 3595 (2008).

8) K. Toko, I. Nakao, T. Sadoh, T. Noguchi, and M. Miyao, Solid-State Electron. 53, 1159 (2009).

9) W. Takeuchi, N. Taoka, M. Kurosawa, M. Sakashita, O. Nakatsuka, and S. Zaima, Appl. Phys. Lett. 107, 022103 (2015).

10) O. Nast, T. Puzzer, L. M. Koschier, A. B. Sproul, and S. R. Wenham, Appl. Phys. Lett. 73, 3214 (1998).

11) M. Kurosawa, N. Kawabata, T. Sadoh, and M. Miyao, Appl. Phys. Lett. 95, 132103 (2009).

12) Ö. Tüzün, Y. Qiu, A. Slaoui, I. Gordon, C. Maurice, S. Venkatachalam, S. Chatterjee, G. Beaucarne, and J. Poortmans, Sol. Energy Mater. Sol. Cells 94, 1869 (2010).

13) Z. Wang, L. Gu, L. P. H. Jeurgens, F. Phillipp, and E. J. Mittemeijer, Nano Lett. 12, 6126 (2012).

14) N. Usami, M. Jung, and T. Suemasu, J. Cryst. Growth 362, 16 (2013).

15) K. Toko, R. Numata, N. Oya, N. Fukata, N. Usami, and T. Suemasu, Appl. Phys. Lett. 104, 022106 (2014).

16) M. Kurosawa, N. Kawabata, T. Sadoh, and M. Miyao, ECS J. Solid State Sci. Technol. 1, P144 (2012).

17) T. Sadoh, J. Park, R. Aoki, and M. Miyao, Jpn. J. Appl. Phys. 55, 03 CB01 (2016).

18) M. Nakata, K. Toko, N. Saitoh, N. Yoshizawa, and T. Suemasu, Scr. Mater. 122, 86 
(2016).

19) S. Hu, A. F. Marshall, and P. C. McIntyre, Appl. Phys. Lett. 97, 082104 (2010).

20) K. Toko, M. Kurosawa, N. Saitoh, N. Yoshizawa, N. Usami, M. Miyao, and T. Suemasu, Appl. Phys. Lett. 101, 072106 (2012).

21) K. Toko, R. Numata, N. Oya, N. Fukata, N. Usami, and T. Suemasu, Appl. Phys. Lett. 104, 022106 (2014).

22) N. Oya, K. Toko, N. Saitoh, N. Yoshizawa, and T. Suemasu, Appl. Phys. Lett. 104, 262107 (2014).

23) K. Toko, K. Nakazawa, N. Saitoh, N. Yoshizawa, and T. Suemasu, Cryst. Growth Des. 15, 1535 (2015).

24) P. Wang, X. Li, H. Liu, S. Lai, Y. Chen, Y. Xu, S. Chen, C. Li, W. Huang, and D. Tang, Mater. Res. Bull. 72, 60 (2015).

25) J.-H. Park, K. Kasahara, K. Hamaya, M. Miyao, and T. Sadoh, Appl. Phys. Lett. 104, 252110 (2014).

26) H. Higashi, K. Kasahara, K. Kudo, H. Okamoto, K. Moto, J.-H. Park, S. Yamada, T. Kanashima, M. Miyao, I. Tsunoda, and K. Hamaya, Appl. Phys. Lett. 106, 041902 (2015).

27) H. Okamoto, K. Kudo, T. Nomitsu, R. Mochii, K. Moto, K. Takakura, and I. Tsunoda, Jpn. J. Appl. Phys. 55, 04EJ10 (2016).

28) M. Nakata, K. Toko, W. Jevasuwan, N. Fukata, N. Saitoh, N. Yoshizawa, and T. Suemasu, Appl. Phys. Lett. 107, 133102 (2015).

29) K. Toko, M. Nakata, W. Jevasuwan, N. Fukata, and T. Suemasu, ACS Appl. Mater. Interfaces 7, 18120 (2015).

30) K. Kasahara, Y. Nagatomi, K. Yamamoto, H. Higashi, M. Nakano, S. Yamada, D. Wang, H. Nakashima, and K. Hamaya, Appl. Phys. Lett. 107, 142102 (2015).

31) T. Antesberger, T. a. Wassner, C. Jaeger, M. Algasinger, M. Kashani, M. Scholz, S. Matich, and M. Stutzmann, Appl. Phys. Lett. 102, 212102 (2013).

32) H. Bracht, N. A. Stolwijk, and H. Mehrer, Phys. Rev. B 43, 14465 (1991).

33) I. Kabacelik, M. Kulakci, and R. Turan, J. Cryst. Growth 419, 7 (2015).

34) M. Kurosawa, A. Ohta, M. Araidai, and S. Zaima, Jpn. J. Appl. Phys. 55, 08NB07 (2016). 
35) N. L. Peterson and S. J. Rothman, Phys. Rev. B 1, 3264 (1970).

36) G. Neumann and C. Tuijn, Self-Diffusion and Impurity Diffusion in Pure Metals: Handbook of Experimental Data (Elsevier, Amsterdam, 2009) P. 56, 62, and 129. 


\section{Figure Captions}

Fig. 1. (Color online) Schematic of the Ag-induced layer exchange crystallization of a-Ge on a glass substrate.

Fig. 2. (Color online) Characterization of the sample with an $\mathrm{Al}_{2} \mathrm{O}_{3}$ interlayer annealed at $300{ }^{\circ} \mathrm{C}$. (a)-(c) Nomarski optical micrographs obtained from the back surface of the samples. (d) Raman spectra obtained from the front and back surfaces of the sample annealed for 10 h. The expected sample structure is schematically shown in (d).

Fig. 3. (Color online) Nomarski optical micrographs obtained from the back surface of the samples with a (a) $\mathrm{SiO}_{2}$, (b) $\mathrm{TiO}_{2}$, (c) $\mathrm{SiN}$, or (d) $\mathrm{GeO}_{2}$ interlayer, annealed at $300{ }^{\circ} \mathrm{C}$ for 10 h.

Fig. 4. (Color online) Nomarski optical micrographs obtained from the back surface of the samples with a (a) $\mathrm{Al}_{2} \mathrm{O}_{3}$, (b) $\mathrm{SiO}_{2}$, (c) $\mathrm{TiO}_{2}$, (d) $\mathrm{SiN}$, or (e) $\mathrm{GeO}_{2}$ interlayer, annealed at $250{ }^{\circ} \mathrm{C}$ for $100 \mathrm{~h}$.

Fig. 5. (Color online) Characterization of the layer-exchanged samples after removing Ag and interlayers. (a) Raman spectra obtained from the front surface of the samples. A spectrum obtained from a bulk Ge substrate is shown for comparison. The FWHMs of the GeGe peaks are shown for each spectra. (b, c) SEM images of the Ge layers where the samples are tilted by $70^{\circ}$. (d, e) EBSD images of the Ge layers in the normal direction, corresponding to the regions framed by white squares. The coloration indicates the crystal orientation according to the legend inserted in (e). 